\title{
Identification of host blood-meal sources and Borrelia in field-collected Ixodes ricinus ticks in north-western Poland
}

\author{
Beata Wodecka', Bogumila Skotarczak ${ }^{1}$ \\ ${ }^{1}$ Department of Genetics, University of Szczecin, Poland \\ Wodecka B, Skotarczak B. Identification of host blood-meal sources and Borrelia in field-collected Ixodes ricinus ticks in north-western Poland. \\ Ann Agric Environ Med. 2016; 23(1): 59-63. doi: 10.5604/12321966.1196853
}

\begin{abstract}
Forest animals play fundamental roles in the maintenance of Ixodes ricinus and Borrelia species in the forest biotope. To identify the forest vertebrate species that are host for I. ricinus and for the recognition of the reservoirs of Borrelia species, the blood-meal of 325 I. ricinus ticks collected at two forest sites in north-western Poland were analysed. Nested PCR was used to detect polymorphisms in a fragment of the mitochondrial 12S rRNA gene for the identification of the hosts species. The products were digested with the restriction enzymes, a combination that allows the identification of 60 vertebrate species, comprising 17 bird, 4 reptile and 39 mammalian species. Host DNA was detected in 244 (75\%) I. ricinus individuals, with the species being detected and classified for 210 (86\%) samples. The restriction patterns resulted in the identification of 14 vertebrate species, including 2 species of birds, lizard, badger, rabbit, deer; most of the samples contained DNA from wild boar (Sus scrofa), red fox (Vulpes vulpes), red deer (Cervus elaphus) and roe deer (Capreolus capreolus). Identification of Borrelia species was based on the flaB gene using nested PCR coupled to RFLP. This method allows the identification of all Borrelia species transmitted by I. ricinus in Europe, including B. miyamotoi and 3 genetic variants of $B$. garinii. In the studied isolates, 2 species belonging to B. burgdorferi sensu lato were identified - B. garinii and B. afzelii, and B. miyamotoi, which are related to relapsing fever borreliae.
\end{abstract}

Key words

blood-meal, Borrelia, reservoir, Ixodes ricinus

\section{INTRODUCTION}

The main vector for the bacteria causing Lyme borreliosis in Europe is the Ixodes ricinus tick. The causative agents of Lyme borreliosis belonging to the Borrelia burgdorferi species complex (B. burgdorferi sensu lato (s.l.)) comprise of at least 19 species with a worldwide distribution [1]. As each species of these tick-transmitted pathogens shows preferences for specific hosts, and is also associated with different clinical manifestations, it is obvious that the eco-epidemiology of Lyme borreliosis agents is very complex [2]. The transmission of $B$. burgdorferi s.l. is affected by molecular processes at the tick-host interface, including mechanisms for the protection of spirochetes against the host's immune response. Molecular biology also increasingly provides important identification tools for the study of tick-borne disease agents and their hosts.

Many species of animals play an essential role in the maintenance of $I$. ricinus and Borrelia in nature, but a specific role is ascribed to forest animals which are the natural sources of infection. The lack of host specificity of I. ricinus has tremendous significance in the spread and maintenance of Borrelia spirochetes in a specific biotope. Infected ticks infect their host when sucking the host's blood, or the tick becomes infected when feeding on an infected animal. Every tick host is a potential reservoir of $B$. burgdorferi s.l., but the proper reservoir species is an animal that enables the persistence of the pathogenic factor, constituting a longterm source of infection for the ticks feeding on it [2]. It has

Address for correspondence: Beata Wodecka Department of Genetics, University of Scecin, Felczaka 3c, 71-412 Szczecin, Poland

e-mail:wodecka.us@gmail.com

Received: 18 Juny 2013; accepted: 22 April 2014 been estimated that ticks can feed on 300 different species of vertebrates (mammals, birds and reptiles), and the capacity to distinguish among the blood meals of haematophagous arthropods has revolutionised our understanding of ectoparasite-host interactions and infectious disease ecology [1]. The methodology for the use of new protocols and molecular markers is under constant development. For the differentiation of reservoirs and Borrelia species, Kirsten and Gray [3] used the mitochondrially encoded $c y t b$ gene as the molecular marker and digested the PCR products using the restriction endonucleases HaeIII and DdeI, a protocol that allowed the authors to distinguish 11 animal species. Pichon et al. [4] identified vertebrate DNA in the tick gut using PCR amplification with universal primers targeting a portion of the 18S rRNA gene, followed by reverse line blot (RLB) hybridisation. In the study of Moran Cadenas et al. [5], a $12 \mathrm{~S}$ rDNA gene fragment was used as a PCR marker, followed by RLB, with the identification of the host DNA from field-collected ticks being possible in $43.6 \%$ of the cases.

The presented work is a continuation of studies concerning the molecular identification of borrelial hosts and Borrelia species through an analysis of the blood meal in $I$. ricinus individuals in north-western Poland [6].

\section{OBJECTIVES}

The aim of the study was to improve the protocols of applied molecular methods. The protocol developed in this study is based on the polymorphism of a mitochondrial $12 \mathrm{~S}$ rRNA gene fragment, allowing the identification of 60 vertebrate species, comprising 17 bird, 4 reptile and 39 mammalian 
species. The identification of Borrelia species was based on the PCR-RFLP protocol with the use of $f l a B$ gene as molecular target and 2 restriction enzymes [7], a method that allows the identification of all Borrelia species transmitted by I. ricinus in Europe.

\section{MATERIALS AND METHOD}

Study material and collection sites of Ixodes ricinus. The study included 325 specimens of $I$. ricinus ticks ( 25 males, 34 females, 266 nymphs) collected in 2 study forest areas in north-western Poland: Zielonczyn (N: 5340'9”; E: 14²4'1") and Pobierowo (N: 54 ${ }^{\circ} 44^{\prime \prime} ;$ E: $\left.14^{\circ} 52^{\prime} 54^{\prime \prime}\right)$. These sites are characterised as mixed forests with a prevalence of European beech (Fagus sylvatica), English oak (Quercus robur) and Scots pine (Pinus sylvestris), and are known as high-risk areas of $I$. ricinus ticks and Borrelia-infected ticks, and are often visited by hikers and mushroom pickers. The ticks were collected with a flannel flag, with which the vegetation was swept up to a height of $1 \mathrm{~m}$, and the collected specimens stored at $-20^{\circ} \mathrm{C}$ until isolation of their DNA.

DNA extraction. DNA was extracted from the ticks according to the phenol-chloroform protocol. All of the tick individuals (nymph or adult) were crushed using a ceramic pestle and suspended in $500 \mu \mathrm{l}$ of $2 \mathrm{X}$ buffer $\left(0.19 \mathrm{M} \mathrm{NH}_{4} \mathrm{Cl}, 0.011 \mathrm{M}\right.$ $\mathrm{KHCO}_{3}$ and $0.024 \mathrm{M}$ EDTA) plus $100 \mu \mathrm{l}$ of Lysis buffer $(0.017$ M SDS, $0.01 \mathrm{M}$ Tris and 0.01 M EDTA) and $1 \mu \mathrm{l}$ of proteinase $\mathrm{K}(20 \mathrm{mg} / \mathrm{ml})$ (BioShop, Canada). The tubes were placed in a $56^{\circ} \mathrm{C}$ water bath for 3 hours. Following this incubation, $300 \mu \mathrm{l}$ of phenol (BioShop) was added, and the tube vortexed for 30 $\mathrm{sec}$ and centrifuged for $10 \mathrm{~min}$. at 9,000 rpm. The supernatant was extracted with $400 \mu \mathrm{l}$ phenol-chloroform (1:1) and then twice with $300 \mu \mathrm{l}$ chloroform (POCH, Poland), vortexing for $30 \mathrm{sec}$ and centrifuging for $10 \mathrm{~min}$. at 9,000 rpm between each extraction. The supernatant was then precipitated by adding $500 \mu \mathrm{l}$ isopropanol (POCH). The pellet was rinsed with $70 \%$ ethanol and air-dried before suspension in TE buffer ( $\mathrm{pH} 8.0$ ). The samples were stored at $-70^{\circ} \mathrm{C}$ prior to the PCR analyses.

Detection of I. ricinus host DNA in blood meal remnants using nested PCR. The mitochondrially encoded $12 S$ rRNA gene was used as the molecular marker for the detection of the tick hosts by nested PCR. This gene has a mosaic structure with regions conserved for vertebrates that may serve as targets for PCR primers and variable regions that may be used as PCR-RFLP markers. The following 2 primer sets were used: outer, 532f12s (5'-CAAACTGGGATTAGATAC-3') and 1102r12s (5'-TGCTTACCTTGTTACGAC-3'), with a product length of approximately $520 \mathrm{bp}$; and inner, 539f12s (5'-GGATTAGATACCCCACTATGC-3') and 1015r12s (5'-TGAGGAGGGTGACGGGCGGT-3'), with product length of approximately $440 \mathrm{bp}$.

The first PCR was performed in a reaction volume of $10 \mu \mathrm{l}$ containing 0.5 U Allegro Taq DNA polymerase (Novazym, Poland), $70 \mathrm{mM}$ Tris- $\mathrm{HCl}\left(\mathrm{pH} 8.6\right.$ at $\left.25^{\circ} \mathrm{C}\right), 16.6 \mathrm{mM}$ $\left(\mathrm{NH}_{4}\right)_{2} \mathrm{SO}_{4}, 3.5 \mathrm{mM} \mathrm{MgCl}_{2}, 0.75 \mu \mathrm{M}$ each deoxyribonucleotide triphosphate (Novazym), 2 pmol each of the 2 outer primers (532f12s and $1102 \mathrm{r} 12 \mathrm{~s}$ ) and $1 \mu \mathrm{l}$ of the supernatant of the processed DNA sample in TB buffer. For the second PCR, $1 \mu \mathrm{l}$ of a 10 -fold dilution of the PCR product of the first reaction was added to $9 \mu \mathrm{l}$ of reaction mixture prepared with inner primers 539f12s and 1015r12s. The PCRs were performed using a T-gradient thermal cycler (Biometra, Germany). The templates were subjected to an initial denaturation step of $94^{\circ} \mathrm{C}$ for $10 \mathrm{~min}$, followed by 40 cycles of $94^{\circ} \mathrm{C}$ for $30 \mathrm{sec}, 60^{\circ} \mathrm{C}$ for $45 \mathrm{sec}$ and $72^{\circ} \mathrm{C}$ for $1 \mathrm{~min}$. The DNA of Cervus elaphus (hunted near Dobra Szczecińska, Zachodniopomorskie province) was used as a positive control. TE buffer was used as the negative control. The PCR products were analysed on $1.5 \%$ agarose gels (BioShop) with the addition of GelView DNA stain (Novazym, Poland) at $5 \mathrm{~V} / \mathrm{cm}$ for 1 hour. The Nova 100 DNA Ladder (Novazym) was used for evaluation of the PCR product size. The results of the PCR were viewed under UV light and computer archived using VisionWorksLS Image Acquisition and Analysis Software (UVP, CA, USA).

Identification of Ixodes ricinus hosts by PCR-RFLP. The DNA amplified using the primer set 539f12s and 1015r12s was digested with enzymes AluI, Cfr13I and Tru1I. These enzymes were selected on the basis of computer analysis (DNAMAN) of the $12 S \mathrm{rDNA}$ gene sequence downloaded from GenBank to obtain the RFLP patterns of 60 vertebrate species: 17 bird, 4 reptile and 39 mammalian species (including Muridae, hares, rabbits, bats, hedgehogs, minks, dormice, roe deer, wild boar, red deer and fallow deer) that might be present in the habitats studied.

Detection of B. burgdorferi s.l. DNA by nested PCR-RFLP. The nested PCR method with 2 primer sets (outer $132 \mathrm{f}$ and $905 \mathrm{r}$ and inner $220 \mathrm{f}$ and $823 \mathrm{r}$ ) used to detect the flaB gene fragment of $B$. burgdorferi s.l. has been described previously $[7,8]$. DNA isolated from a reference strain of B. burgdorferi s.s. IRS (German Collection of Microorganisms and Cell Cultures - DSMZ, Germany) was used as the positive control, and TE buffer as the negative control. The PCR products were separated on $1.5 \%$ agarose gels with the addition of GelView DNA stain at $5 \mathrm{~V} / \mathrm{cm}$ for 1 hour. The Nova 100 DNA Ladder was used for evaluation of the product. The results of the PCR were viewed under UV light and archived as described above.

The flaB gene fragments amplified using the primer set $220 \mathrm{f}$ and $823 \mathrm{r}$ were digested with enzymes HpyF $\underline{3}$ I and Ecl136II (Fermentas, Lithuania) to obtain RFLP patterns of different Borrelia species, as described previously [7]. The digestion products were analysed on $3 \%$ agarose gels at $5 \mathrm{~V} / \mathrm{cm}$ for 2 hours and archived as described above.

\section{RESULTS}

Host species determination. Host DNA was detected in 244 I. ricinus individuals; 15 types of restriction patterns consistent with those from GenBank based on the analysis of the $12 S$ rRNA sequence were obtained for 210 (86\%) of the samples. A list of the observed restriction patterns characteristic for each species of vertebrate is presented in Table 1 . The results from the remaining 34 samples (14\%) did not allow identification of the host to the species level. The characteristic restriction patterns obtained in the digested nested PCR products for 4 selected vertebrate species are shown in Figure 1.

Borrelia species determination. The DNA of Borrelia spirochetes was detected using nested PCR in 11 of the 244 I. ricinus isolates, which was $4.5 \%$ of the population showing 
Table 1. Restriction patterns obtained after digestion of the mitochondrial 12S rRNA gene sequence with enzymes Alul, Cfr13l and Tru1l for vertebrate selected species

\begin{tabular}{|c|c|c|c|}
\hline Host species & Enzyme & $\begin{array}{l}\text { Restriction } \\
\text { pattern }\end{array}$ & $\begin{array}{l}\text { No. of I. ricinus } \\
\text { individuals } \\
\text { with the host } \\
\text { DNA (n/\%) }\end{array}$ \\
\hline Sus scrofa (wild boar) & Alul & $167-274$ & $39 / 18.57$ \\
\hline Vulpes vulpes (red fox) & Alul & $52-76-304$ & $38 / 18.09$ \\
\hline Cervus elaphus (red deer) & $\begin{array}{l}\text { Alul } \\
\text { Tru1l }\end{array}$ & $\begin{array}{c}83-354 \\
28-57-95-257\end{array}$ & $38 / 18.09$ \\
\hline Capreolus capreolus (roe deer) & $\begin{array}{l}\text { Alul } \\
\text { Tru1l }\end{array}$ & $\begin{array}{c}83-354 \\
10-23-85-95-224\end{array}$ & $34 / 16.19$ \\
\hline Accipiter gentilis (northern goshawk) & Alul & $41-175-223$ & $24 / 10.43$ \\
\hline Myodes glareolus (bank vole) & Alul & $42-89-300$ & $16 / 7.62$ \\
\hline Lacerta viridis (green lizard) & Alul & $41-400$ & $14 / 6.67$ \\
\hline Meles meles (European badger) & Alul & $52-175-209$ & $1 / 0.48$ \\
\hline Dama dama (fallow deer) & $\begin{array}{l}\text { Alul } \\
\text { Tru1l }\end{array}$ & $\begin{array}{l}83-354 \\
85-352\end{array}$ & $1 / 0.48$ \\
\hline Natrix natrix (grass snake) & $\begin{array}{l}\text { Alul } \\
\text { Cfr13l }\end{array}$ & $\begin{array}{c}206-231 \\
436\end{array}$ & $1 / 0.48$ \\
\hline $\begin{array}{l}\text { Orytolagus cuniculus (European } \\
\text { rabbit) }\end{array}$ & $\begin{array}{l}\text { Alul } \\
\text { Cfr13I }\end{array}$ & $\begin{array}{c}82-149-200 \\
92-339\end{array}$ & $1 / 0.48$ \\
\hline $\begin{array}{l}\text { Plecotus austriacus (grey long-eared } \\
\text { bat) }\end{array}$ & $\begin{array}{l}\text { Alul } \\
\text { Tru1l }\end{array}$ & $\begin{array}{c}98-158-173 \\
28-88-147-170\end{array}$ & $1 / 0.48$ \\
\hline Castor fiber (European beaver) & $\begin{array}{l}\text { Alul } \\
\text { Tru1l }\end{array}$ & $\begin{array}{c}83-354 \\
85-131-222\end{array}$ & $1 / 0.48$ \\
\hline Ciconia nigra (black stork) & $\begin{array}{l}\text { Alul } \\
\text { Cfr13l }\end{array}$ & $\begin{array}{c}206-234 \\
39-398\end{array}$ & $1 / 0.48$ \\
\hline
\end{tabular}

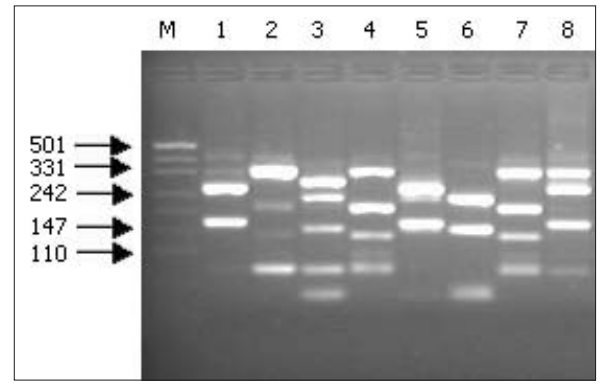

Figure 1. Restriction patterns obtained for the hosts of $I$. ricinus ticks (collected in Zielonczyn area) by the digestion of mitochondrial gene $12 S r R N A$ fragments and the products of nested-PCR reactions with Alul: $M-D N A$ molecular weight marker MW 501

1,5,8 - Sus scrofa; 3 -Myodes glareolus; 6 - Accipiter gentilis; 2, 4, 7-Cervus elaphus

host DNA. Restriction analysis of the nested PCR product using the 220f and 823r primers and the HpyF3I enzyme generated 3 restriction patterns characteristic for 3 Borrelia species (Fig. 2): 2 species belonging to B. burgdorferi s.l., $B$. garinii and B. afzelii, and B. miyamotoi, which is related to relapsing fever borreliae. The results of the identification of the Borrelia species using the PCR-RFLP method is shown in Figure 2. B. garinii DNA was detected along with DNA from 2 host species (Myodes glareolus and Accipter gentilis) in nymphs, and DNA from B. afzelii and 2 hosts (Sus scrofa and Oryctolagus cuniculus) was also detected in nymphs. DNA from B. miyamotoi and 3 species of vertebrates (Capreolus capreolus, Cervus elaphus and Sus scrofa) was detected in 2 nymphs and 1 male.

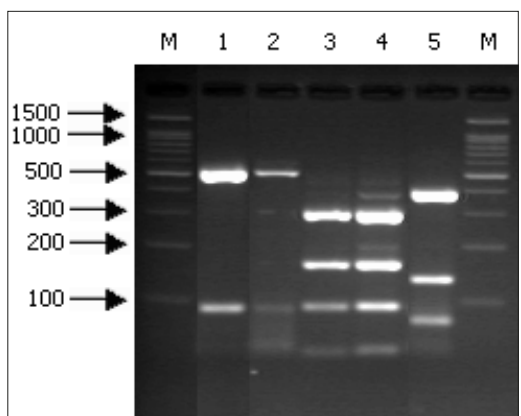

Figure 2. Restriction patterns obtained for Borrelia species after the digestion of $f a B$ gene fragments with HpyF3I (identification results for the Zielonczyn area).

M - DNA molecular weight marker MW501; 1, 2 -

B. miyamotoi; 3, 4-B. afzelii; 5 - B. garinii.

\section{DISCUSSION}

The capacity to distinguish the blood meals of haematophagous arthropods has revolutionised our understanding of ectoparasite-host interactions and infectious disease ecology [1]. Such an indirect method of identification of I. ricinus hosts was applied, as based on unfed ticks, in the presented work. Each DNA isolate obtained from a single tick was useful for the identification of both host species and Borrelia species. The host species was determined with great precision based on host blood meal remnants in adult and nymphal I. ricinus ticks using species-specific restriction patterns with a PCR-RFLP protocol. This method may be very useful for the development of studies concerning the reservoir of $B$. burgdorferi s.l. spirochetes because the reservoirs for all of the Borrelia species have not been determined to date.

The protocol presented in this study improves on the method of Kirsten and Gray [3], allowing the identification of 60 vertebrate species, including 17 birds, 4 reptiles and 39 mammals; DNA of host species was detected in 210 I. ricinus individuals $(86 \%)$. In similar studies, the detectability of host DNA in nymphal ticks was much lower. The low level of detected host DNA was obtained in a study conducted in Spain [9] in which host DNA was detected only in $37.7 \%$ of the ticks, and in Ireland with $49.4 \%$ of host DNA detectability [4], whereas the DNA of vertebrate hosts was detected in 53.5\% of Borrelia-infected ticks in an earlier study in Poland by the authors of the current study [6]. It is difficult to compare DNA results among studies because of differences in the number of ticks, method of DNA isolation, and molecular target for host DNA detection. However, in studies in which the entire population of ticks were tested, the level of detection of host DNA appeared to depend on the DNA isolation method. The method described by Guy and Stanek [10] using ammonium hydroxide is the most frequent and simplest protocol for DNA isolation from hard ticks (Ixodidae), yet it is also the least effective method. Studies applying 2 isolation protocols, the first with ammonium hydroxide and the second with Chelex, showed higher levels of host DNA detection for ticks prepared with the Chelex protocol $(72.8 \%)$ than with ammonium hydroxide (48.4\%) [11]. The phenol-chloroform protocol used in presented study is the most time-consuming method, but it appears to be the most effective for host DNA detection. Further studies are required to compare this protocol with those using ammonium hydroxide. 
The presented protocol allows for precise identification of individual host species in that 14 species of forest-dwelling animals were successfully detected and classified, and may be considered as possible or natural reservoirs of $B$. burgdorfer $i$ s.l. spirochetes in the selected area. The described protocol is a variation of an earlier method [6] developed to identify as much as 60 species of tick hosts. In contrast to the presented work, other protocols allow identification only at the genus level or larger group of organisms, such as songbirds, gamebirds, small mammals, squirrels and ruminants $[4$, $9,11]$. However, studies of the ticks collected from birds revealed that among songbirds only 2 species are important, blackbird (Turdus merula) and song thrush (T. philomelos) $[12,13]$, which suggests the necessity for a precise method for tick host identification.

The most common host species detected in the ticks were large mammals, i.e., red deer (C. elaphus), roe deer (C. capreolus), wild boar (S. scrofa) and red fox (V. vulpes), results which are in accordance with the results of previous studies. When the entire population of collected nymphs were tested for host DNA, ruminants predominated or were one of predominant groups of vertebrate hosts $[4,11]$. The indicated species, particularly roe deer and red deer, are considered as the main hosts of the $I$. ricinus mature stage. However, a comparison of the 2 methods of tick collection from large mammals [14] revealed that, in collecting ticks from living animals (live method), most of the feeding larvae and nymphs are absent. In contrast, the method of collecting from the separated parts of hunted animals (destructive method) allows establishment of the actual proportion of tick stages, which fluctuated from $62.8 \%-68 \%$ for larvae, from $25.9 \%-31.8 \%$ for nymphs, and from $5.4 \%-6.1 \%$ for adults. The mean number of ticks collected from an individual animal using the destructive sampling method was $40-$ 60 times higher than for the live method. The prevalence of large-mammal DNA detected in non-engorged nymphs (acquired during the feeding process in the larval stage) found in the present and other studies is in accordance with the above-described findings.

Vertebrate tick hosts that are not associated with the life cycle of Borrelia may interrupt the cycle or serve as competent reservoirs and participate in the enzootic cycle of these bacteria $[12,15]$. Animals that retain the pathogen and constitute a source of infection for a long time to allow ticks to feed on them are competent reservoirs of B. burgdorferi s.l. [1]. However, even incompetent hosts are able to participate in the circulation of $B$. burgdorferi s.l. because of the so-called co-feeding phenomenon [16]. Detection of the pathogen in the tissue of such animals reveals susceptibility of the host to the infection, but does not necessarily mean that the animal host is able to transfer B. burgdorferi through feeding ticks [2].

In Europe, animal reservoirs have been determined with regard to approximately 40 species of birds and mammals [2, 17]. Thus far, it has been found that large forest mammals, such as roe deer, red deer and wild boar, which are the basic hosts for adult $I$. ricinus, are not able to constitute reservoirs for the species belonging to the B. burgdorferi s.l. complex [17]. Although the DNA of the roe deer C. capreolus has been identified in 34 samples from ticks, although this species does not seem to have any relevance as a reservoir of B. burgdorferi s.l. in north-western Poland because the DNA of a Borrelia spirochete was present in only 1 nymph of I. ricinus $(2.9 \%)$ - B. miyamotoi of the relapsing fever borreliae group. C. capreolus plays a short-term role as a Borrelia host, enabling the transmission to the vector organism during the process of feeding: when a tick acquires spirochetes from the subcutaneous tissue in the direct area of an earlier bite by another infected tick [16]. The studies of Telford et al. [18] in addition to earlier studies by the authors of the presented study $[6,19]$, have proved that roe deer is not an important reservoir of $B$. burgdorferi s.l.

There are data concerning the possibility of surviving spirochetes in the blood of red deer (Cervus elaphus), remaining in their skin and an absence of the possibility to survive $[17,18]$. The studies of Wodecka [20] have provided negative results for the occurrence of B. burgdorferi s.l. spirochetes in the DNA isolated from red deer tissues and from the ticks found on them. In the presented work, the DNA of C. elaphus was identified in 38 individuals of I. ricinus; however, the DNA of Borrelia was detected only in a single male tick (2.6\%), and the species was B. miyamotoi. These results confirm that C. elaphus does not function as a $B$. burgdorferi s.l. reservoir.

It has been reported that Sus scrofa is not a competent reservoir of $B$. burgdorferi s.l., but these animals are the main hosts of the adult stage of I. ricinus [6]. In the presented work, the DNA of S. scrofa was identified in 39 individuals of I. ricinus, and the DNA of B. afzelii and B. miyamoto $i$ was detected in 2 nymphs (5.1\%).

Reservoir competence for B. burgdorferi spirochetes has not yet been confirmed for Vulpes vulpes. However dogs, the domesticated relatives of red fox, often suffer from Lyme borreliosis [21, 22, 23, 24]. The studies of Heidrich et al. [25] have proven the possibility of $B$. burgdorferi s.l. spirochetes occurring in the skin of $V$. vulpes. In the present work, fox DNA was detected in 38 samples, but none of these samples contained Borrelia spirochetes.

According to Gern [2], Myodes glareolus (bank vole) is thought to be a natural reservoir of B. burgdorferi s.l. spirochetes. However, in the opinion of Talleklint and Jaenson [26], M. glareolus cannot serve as a reservoir of the spirochetes because the infected bank voles easily die during the winter. In the current study, the DNA of Myodes glareolus was found in 16 samples, and B. garinii DNA was detected in $2(12.5 \%)$ samples.

Fallow deer (Dama dama) is not recognised as a competent reservoir of $B$. burgdorferi s.l. This assertion was confirmed by the studies of Talleklit and Jaenson [27] in south-central Sweden where the registered frequency of infection with Borrelia spirochetes was low (7-10\%), and was explained by the occurrence of a large number of fallow deer in this region. In the presented study, the presence of D. dama DNA was identified only in $1 \mathrm{tick}$, and spirochete DNA was not detected in this sample.

The studies of Gern and Sell [28] conducted in Switzerland indicate that Meles meles may act as a reservoir of B. afzelii. However, there is lack of convincing data concerning the ecological relevance of badgers with regard to Lyme borreliosis in Europe. In the current study, the DNA of $M$. meles was detected only in one tick, whereas the DNA of B. burgdorferi s.l. was not present in this sample.

The other 7 identified vertebrate species with genetic material present in the blood found in the tick's alimentary tract were Accipiter gentilis (northern goshawk) in 24 samples and Lacerta viridis (lizard) in 16 samples. The DNA of the following species was found in only 1 sample: Natrix natrix 
(grass snake), Ciconia nigra (black stork), Castor fiber (European beaver), Plecotus austriacus (grey long-eared bat) and Oryctolagus cuniculus (European rabbit). These are likely accidental hosts because they do not appear on the list of reservoir species [2]. Among these species, only the DNA of goshawk and rabbit occurred together with the genetic material of B. afzelii and B. miyamotoi, respectively.

The identified species of vertebrates play a large part in the ecology of Lyme borreliosis, but only M. glareolus constitutes a reservoir for Borrelia spirochetes. The other species do not exhibit reservoir competence with regard to B. burgdorferi s.l.; however, as significant hosts for I. ricinus ticks, these species are elements of the enzootic cycle of the bacterium, enabling the tick to survive and reproduce. The fact that these animals are short-lasting hosts for some Borrelia species is essential in enabling the bacteria to survive and transfer to the vector during the feeding process. Unfortunately, in the presented study it was not possible to determine which of these animals is the most important for spreading Borrelia infections because the degree of infection was small: the DNA of $B$. burgdorferi s.l. was detected only in a few individuals of I. ricinus that had fed on $M$. glareolus, S. scrofa, C. capreolus, C. elaphus, O. cuniculus and A. gentilis.

In summary, the modification of a previous protocol allowed the detection of host DNA with the highest efficiency and accuracy of the individual identified species. The method confirmed the finding that the main hosts of all of the stages of $I$. ricinus are large mammals, particularly deer, wild boars and foxes. Undoubtedly, all of the identified animals have essential roles in the circulation of Borrelia spirochetes, and they also enable the survival and reproduction of $I$. ricinus ticks. Moreover, these species also serve as short-lasting hosts for some Borrelia species, enabling their survival and transmission to feeding vectors.

\section{Acknowledgements}

The research was supported financially by Grant No. N N303 806140 from the National Science Centre, Kraków, Poland.

\section{REFERENCES}

1. Mannelli A, Bertolotti L, Gern L, Gray J. Ecology of Borrelia burgdorferi sensu lato in Europe: transmission dynamics in multi-host systems, influence of molecular processes and effects of climate change. FEMS Microbiol Rev. 2012; 36: 837-861.

2. Gern L. Borrelia burgdorferi sensu lato, the agent of Lyme borreliosis: life in the wilds. Parasite 2008; 15: 244-247.

3. Kirstein F, Gray JS. A molecular marker for the identification of the zoonotic reservoirs of Lyme borreliosis by analysis of the blood meal in its European vector, Ixodes ricinus. Appl Environ Microbiol. 1996; 62: 4060-4065.

4. Pichon B, Rogers M, Egan D, Gray J. Blood-meal analysis for the identification of reservoir hosts of tick-borne pathogens in Ireland. Vector Borne Zoonotic Dis. 2005; 5: 172-180.

5. Morán Cadenas F, Rais O, Humair PF, Douet V, Moret J, Gern L. Identification of host bloodmeal source and Borrelia burgdorferi sensu lato in field-collected Ixodes ricinus ticks in Chaumont (Switzerland). J Med Entomol. 2007; 44(6): 1109-1117.

6. Wodecka B, Rymaszewska A, Skotarczak B. Host and pathogen DNA identification in blood meals of nymphal Ixodes ricinus ticks from forest parks and rural forests of Poland. Exp Appl Acarol. 2013; 62: 543-555.
7. Wodecka B. FlaB gene as a molecular marker for distinct identification of Borrelia species in environmental samples by the PCR-restriction fragment length polymorphism method. Appl Environ Microbiol. 2011; 77: 7088-7092.

8. Wodecka B, Leońska A, Skotarczak B. A comparative analysis of molecular markers for the detection and identification of Borrelia spirochetes in Ixodes ricinus. J Med Microbiol. 2010; 59: 309-314.

9. Estrada-Pena A, Osacar JJ, Pichon B, Gray J. Host and pathogen detection for immature stages of Ixodes ricinus (Acari: Ixodidae) in North-Central Spain. Exp Appl Acarol. 2005; 37: 257-268.

10. Guy EC, Stanek G. Detection of Borrelia burgdorferi in patients with Lyme disease by the polymerase chain reaction. J Clin Pathol. 1991; 44: 610-611.

11. Allan BF, Goessling LS, Storch GA, Thach RE. Blood meal analysis to identify reservoir hosts of Amblyomma americanum ticks. Emerg Infect Dis. 2010; 16: 433-440.

12. Olsen B. The role of birds in the ecology and epidemiology of Lyme borreliosis and ehrlichiosis. Infect Dis. 2003; 2: 4-7.

13. Michalik J, Wodecka B, Skoracki M, Sikora B, Stańczak B. Prevalence of avian-associated Borrelia burgdorferi s.l. genospiecies in Ixodes ricinus ticks collected from blackbirds (Turdus merula) and song thrushes (T. philomelos). Int J Med Microbiol. 2008; 298: 129-138.

14. MacIvor KM, Horak IG, Holton KC, Petney TN. Comparison of live and destructive sampling methods of determining the size of parasitic tick populations. Exp Appl Acarol. 1987; 3: 131-143.

15. Michalik J, Skotarczak B, Skoracki M, Wodecka B, Sikora B, Hofman T, Rymaszewska A, Sawczuk M. Borrelia burgdorferi sensu stricto in yellow-necked mice and feeding Ixodes ricinus ticks in a forest habitat of west central Poland. J Med Entomol. 2005; 5: 850-856.

16. Richter D, Allgöwer R, Matuschka FR. Co-feeding transmission and its contribution to the perpetuation of the Lyme disease spirochete Borrelia afzelii. Emerg Infect Dis. 2002; 8: 1421-1425.

17. Kurtenbach K, De Michelis S, Etti S, Schafer SM, Sewell HS, Brade V, Kraiczy P. Host association of Borrelia burgdorferi sensu lato - the key role of host complement. Trends Microbiol. 2002; 10: 74-79.

18. Telford SR, Mather TN, Moore SI, Wilson ML, Spielman T. Incompetence of deer as reservoir of the Lyme disease spirochete. Am J Trop Hyg. 1988; 39: 105-109.

19. Skotarczak B, Adamska M, Sawczuk M, Maciejewska A, Wodecka B, Rymaszewska A. Coexistence of tick-borne pathogens in game animals and ticks in western Poland. Vet Med. 2008; 53(12): 668-675.

20. Wodecka B. Significance of red deer (Carvus elaphus) in the ecology of Borrelia burgdorferi s.1. Wiad Parazyt. 2007; 53(3): 231-237.

21. Magnarelli LA, Anderson JF, Schreier AB. Persistence of antibodies to Borrelia burgdorferi in dogs of New York and Connecticut. J Am Vet Med Assoc. 1990; 196(7): 1064-1068.

22. Wodecka B, Rymaszewska A, Sawczuk M, Skotarczak B. Detectability of tick-borne agents DNA in the blood of dogs, undergoing treatment for borreliosis. Ann Agric Environ Med. 2009; 16: 33-38.

23. Skotarczak B, Wodecka B. Molecular evidence of the presence of Borrelia burgdorferi sensu lato in blood samples taken from dogs in Poland. Ann Agric Environ Med. 2003; 10: 113-115.

24. Skotarczak B, Wodecka B. Identification of Borrelia burgdorferi genospecies inducing Lyme disease in dogs from western Poland. Acta Vet Hun. 2005; 53: 13-21.

25. Heidrich J, Schönberg A, Steuber S, Nöckler K, Schulze P, Voigt WP, Schein E. Investigation of skin samples from red foxes (Vulpes vulpes) in eastern Brandenburg (Germany) for the detection of Borrelia burgdorferi s. 1. Zentralbl Bakteriol. 1999; 289(5-7): 666-672.

26. Talleklint L, Jaensen TG. Is the small mammal (Clethrionomys glareolus) or the tick vector (Ixodes ricinus) the primary overwintering reservoir for the Lyme borreliosis spirochete in Sweden? J Wild Dis. 1995; 31: 537-540.

27. Tälleklint L, Jaenson TG. Relationship between Ixodes ricinus density and prevalence of infection with Borrelia-like spirochetes and density of infected ticks. J Med Entomol. 1996; 33(5): 805-811.

28. Gern L, Sell K. Isolation of Borrelia burgdorferi sensu lato from the skin of the European badger (Meles meles) in Switzerland. Vec Bor Zoon Dis. 2009; 9(2): 207-208. 